\title{
An Analysis of Causes and Countermeasures for Reconstruction and Integration of Automobile Industry in China
}

\author{
Mengchun Ding \\ School of Economics and Management, Changchun University of Science and Technology \\ Changchun 130022, China \\ Tel: 86-431-8203-0456_E-mail: dingmengchun312@163.com \\ Ying Wang \& Shiruo Wang \\ School of Economics and Management, Changchun University of Science and Technology \\ Changchun 130022, China
}

Received: December 26, 2010 Accepted: January 14, $2011 \quad$ doi:10.5539/ass.v7n5p215

\begin{abstract}
In the past few years, the automobile industry in China has been rapidly growing, which has great effect on boosting economic development in China. However, the disperse, small-scale and bad condition of automobile industry still has not been enhanced, which will seriously restrain further development of automobile industry in China. This article started out from the status quo of reconstruction and integration of automobile industry, analyzed causes for reconstruction and integration of automobile industry in China and put forward countermeasures for reconstruction and integration of automobile industry in China.
\end{abstract}

Keywords: Automobile industry, Reconstruction, Integration, Analysis of cause

\section{The status quo of reconstruction and integration of automobile industry in China}

In the recent several years, the automobile industry in China has been rapidly developed and voice for reconstruction has also become stronger. There have been various cases of reconstruction of automobile industry, but there were only the following two successful cases of reconstruction: reconstruction of FAW and Tianjin Automobile Industry Co., Ltd., and reconstruction of Shanghai Automotive Industry Corporation (SAIC) and Nanjing Automobile (Group) Corporation. In 2002, FAW reorganized Tianjin Automobile Industry Co., Ltd, which can be said to be a model in cases of reconstruction in automobile industry in China. FAW purchased $60 \%$ of shares of all the $84.97 \%$ shares held by Tianjin Automobile Industry Co., Ltd in Tianjin Faw Xiali Automobile Co., Ltd., and purchased at a time all the 75\% share ownership held by China in Huali Corporation --- subsidiary of Tianjin Automobile Industry Co., Ltd. FAW made up for its blackness in domestic economy car by means of reconstruction. Reconstruction of Shanghai Automotive Industry Corporation (SAIC) and Nanjing Automobile (Group) Corporation also deserved to be referred. For quite a long time, SAIC was weak in terms of commercial vehicle, while Nanjing Automobile (Group) Corporation operated well in plate of assets in commercial vehicle and had ranked the third in domestic automobile industry. Thus, these two enterprises had strong complementarity in terms of business. In December 2007, the two enterprises came to an agreement and completed the reconstruction. SAIC Motor controlled by SAIC made a contribution of 2.095 billion Yuan to purchase assets of finished automobile and tight components and parts of Yuejin Motor Group which was the controlling shareholder of Nanjing Automobile (Group) Corporation.

Since "Plan on Adjusting and Revitalizing the Auto Industry" was issued in April 2009, enthusiasm in reconstruction of domestic automobile enterprises was on an increase. In May 2009, stock transfer of GAIG and Changfeng Motor pulled the prelude of a new round of reconstruction of automobile industry. In November 2009 , Chang'an Automotive Group owned by China Weaponry Equipment Group purchased assets of Changhe Auto, Hafei Motor, Dong'an Auto-Engine, Changhe Suzuki and Dong'an Mitsubishi owned by CNAC with 17 billion Yuan, which had been the largest reconstruction in automobile industry in China in the past several years.

In 2009, oversea reconstruction of China automobile industry was also frequently witnessed. BAW Group and FJMG signed the acquisition agreement, in which BAW Group acquired $40 \%$ shares of all the $50 \%$ share ownership held by FJMG in Fujian Daimler Auto and Daimler Lightweight Car (Hongkong) Co. Ltd. Merely 
held 50\% of all the shares. In October 2009, Tengzhong Heavy Industrial Machinery Co. Ltd acquired Hummer business owned by General Motors Corporation. In December, BAW Group successfully purchased relevant intellectual property of Sweden Saab Automobile AB at a price of 0.2 billion US dollars, which was the first successful case that domestic automobile enterprises acquired advanced whole set of technology in finished automobile in European and American countries. In December, Geely successfully purchased Volvo saloon car.

Thus, it can be said, issue of "Plan on Adjusting and Revitalizing the Auto Industry" in 2009 accelerated and stimulated reconstruction of automobile industry in China and enabled automobile enterprises to rapidly expand market shares, adjust market structure and enhance competitive force.

\section{Causes for reconstruction of automobile industry in China}

\subsection{Development of domestic automobile industry accelerates reconstruction and integration of automobile industry}

Firstly, the automobile industry in China is disperse, small-scale and weak and has not formed a complete industrial chain, which causes too high cost of production of automobiles. Automobile enterprises in China are mainly distributed in Changchun, Beijing, Chongqing, Shanghai, Ningbo, Taizhou, Wenzhou, Tianjin, Guangzhou and Hangzhou, etc. Cities which have the highest gross output value of automobile industry mainly include Changchun, Beijing, Tianjin, Shanghai, Guangzhou and Chongqing. Generally speaking, the automobile industry in China is distributed dispersedly. Furthermore, quite a large number of automobile enterprises are with small scale and are far from attaining scale economy effect. Under the circumstance of economic globalization, these enterprises almost have no competitive force. In addition, enterprises which manufacture finished automobiles and enterprises which manufacture components and parts in the chain of automobile chain are in a separate condition, which might lead to too high cost of production of automobiles and relatively low profits. The status quo of development of domestic automobile industry calls for automobile enterprises to conduct reconstruction, optimize industrial structure, optimize resource allocation and improve international competitive force.

Secondly, excess production capacity is a pertinacious illness in automobile industry. In 2009, the total sales volume of automobile industry in China was 13.6448 million, with 11.8933 million automobiles in enterprises which ranked the top ten in sales, which accounted for $87.16 \%$ of the total sales amount of automobiles. According to statistics of China Association of Automobile Manufacturers, there were approximately 10 enterprises with a sales amount of "zero". Thus, it can be found, the issue of excess production capacity in automobile industry in China is quite serious.

\subsection{Foreign investment drives reconstruction and integration of automobile industry in China}

Since the later 80s in the Twentieth Century, oversea automobile enterprises began to make investment in China and at the very earliest, they made joint investment with the contract alliance of methods of technology licensing and technology outsourcing, etc. After the 90 s, joint venture was the primary means, such as, joint venture of FAW and Volks Wagen, joint venture of Dongfeng Automobile and Citroen in France and joint venture of SAIC and General Motors Corporation. From the year 2000, with gradual adjustment of industrial policies in automobile industry (cancelling limitation of domestication, limitation of stock rate of motors and limitation of service trade field), multinational corporations began to extend to the upper stream and downstream of the value chain and bring China into the global automobile operation system. Afterwards, the strategic alliance of automobile enterprises also became gradually diversified. In addition to joint ventures which held equal shares and manufactured finished automobiles, more and more absolutely holding joint ventures were established which manufactured motors. And joint ventures for market sales also started to turn up (such as SVW Sales Company, Dongfeng Yulong Auto Sales Company, FAW Toyota Sales Company and FAW Mazda Sales Company, etc.)

Entry of foreign investment in China drives development of the automobile industry, but also poses a threat to domestic automobile enterprises. Foreign automobile enterprises enter China market after being reorganized, which makes the comprehensive technology of automobile industry, especially saloon car industry in China greatly improved and brings certain effects to development of saloon cars in China. It is believed that, foreign investment has pushed forward development of automobile manufacturing enterprises to a large extent, but hasn't had obvious spillover effect on automobile enterprises. Entry of foreign investment is not aimed to foster the automobile industry in China, but to take over the vast market of China and make enormous profits.

\subsection{Financial crisis speeds up reconstruction and integration of automobile industry in China}

Attacked and influenced by the international financial crisis, export of automobiles in China was obstructed. Under influences of the financial crisis, the international automobile industry is faced up with a new round of reshuffle and premature consumption of automobile in China and over-investment and foam in automobile market booming are brought to exposure. In order to China automobile enterprises to survive in the cruel market 
competition, merger, reconstruction and integration is unavoidable. In 2009, Tengzhong Heavy Industrial Machinery Co. Ltd. acquired Hummer business owned by General Motors Corporation and Geely successfully purchased Volvo. From these reconstruction actions, it is obvious that, automobile enterprises with self-owned brands also attempted to resort to this reconstruction environment and policy to strengthen their competitive strength. The financial crisis provided an opportunity and challenge to automobile enterprises in China. This financial crisis caused automobile enterprises manufacturing finished cars and components and parts of cars to suffer from the crisis, while it offered an opportunity for Chinese automobile enterprises to make reconstruction and integration of automobile industry in developed countries within a global scope. Thus, automobile industry in China ought to make full use of this opportunity and acquire resources of motors, finished cars and components and parts of cars required for development of the enterprises, including technical resources, manufacturing resources and product resources. Domestic automobile industry should give full play to the learning effect and fulfill the synergistic effect of resources up to the hilt. Simultaneously, introduction of international excellent talents in automobile industry forms talent accumulation for self-owned brand undertaking in domestic automobile industry.

\subsection{National policies facilitates reconstruction and integration of domestic automobile industry}

In the past few years, in order to direct automobile industry to realize rapid and coordinated development, the country has issued in succession a series of policies and strategies to encourage automobile enterprises to expand and become stronger through merger. As early as in 2004, it was stipulated in "Automotive Industry Development Policy", existing automobile enterprises should be encouraged to make a joint reconstruction with the link of assets to enhance the competitive power of automobile industry. At the end of 2006, the National Development and Reform Commission released "Opinion on Adjusting the Structure of the Motor Vehicle Industry", in which it was clearly proposed to facilitate automobile manufacturing enterprises to make a joint reconstruction. Under facilitation of the "Opinion", cooperation between SAIC and Nanjing Automobile (Group) Corporation was successful. "The 'Eleventh Five-Year' Development Plan for China Automobile Industry" issued in 2007 stipulated, China automobile industry should have one or two large-scale automobile manufacturing enterprises with an annual production capacity of more than 2 million vehicles, several backbone automobile manufacturing enterprises with an annual production capacity of over 1 million vehicles, and another about ten medium-and-small-scale automobile manufacturing enterprises, especially small-scale enterprises with an annual production and sales capacity of less than 100,000 vehicles should be listed as candidates for acquisition and reconstruction. It was clearly stipulated in "Plan on Adjusting and Revitalizing the Auto Industry" issued in 2009, nationwide reconstruction was supported in large-scale automobile enterprises, such as FAW, Dongfeng, SAIC and Chang'an, etc. In the meanwhile, local reconstruction was also supported in BIC, Chery Automobile and Sinotruk. With support of all the above policies, reconstruction of automobile enterprises was uninterrupted in 2009, and reconstruction of automobile industry will represent the general trend in the future. In the situation when sales of automobiles in the market posed a threat of declining, the country released relevant policies and offered direction, which would be helpful to promote rational and effective ongoing of corporate reconstruction and integration. Relevant departments of the country have already set about formulating directive opinions to promote reconstruction and integration of automobile enterprises, which would facilitate reconstruction and integration of automobile industry in China to a large degree.

\section{Suggestions to facilitate reconstruction and integration of automobile industry in China}

\subsection{Relevant policies to improve reconstruction of automobile enterprises}

In the process of implementation of reconstruction of automobile industry with the target of optimizing industrial structure and increasing industrial profits, support of corresponding supportive policies is required. Firstly, we should break local protectionism. In order to promote development of Chinese automobile industry, relevant departments of the government have to carry out and complete relevant laws with the least delay possible to restrain protection behaviors of local government out of consideration of its own interests and abolish a variety of rules and regulations that constrain fair competition. Secondly, we should carry out policies and measures to support reconstruction of automobile industry, offer tax preference for those enterprises of reconstruction, reduce cost in reconstruction of automobile industry, simplify the multiple approval procedures for reconstruction and improve efficiency of reconstruction. Thirdly, we have to formulate policies for automobile industry in a scientific way which can play a clearly directive role in development of automobile industry and properly resolve such issues of asset transfer of enterprises, debt check and disposal and distribution of fiscalit and interests.

\subsection{To enhance administrative intervention of the government in reconstruction and integration of enterprises}

Reconstruction of automobile industry in China ought to belong to a market behavior, in which limited resources flow to enterprises with higher utility rate of these resources through leading of the market. However, aspiration of reconstruction in some enterprises is not strong, so coordination of interests of all parties involved in the reconstruction needs guidance and intervention of the government. Firstly, cross-region reconstruction needs participation of the government. Unavoidably, cross-region reconstruction of automobile industry might touch 
interests of enterprises within the regions and reconstruction of cross-administrative boundary might also be encountered with some problems that they themselves are unlikely to resolve. Then, this requires the government to start out from the long term development of the entire industry, take administrative means at a higher level, balance interests of enterprises in different regions and eliminate all blockade to the reconstruction. Intervention of administrative means by the government brings faster effect than market regulation and is also likely to reduce a large amount of negotiation expenses in the process of reconstruction of enterprises. The government coordinates a variety of specific affairs in the process of reconstruction, so the efficiency of reconstruction will be more obvious. Secondly, undeveloped capital market and incomplete investment agent call for the government to direct the reconstruction. Participation of the government in the reconstruction means that we can use lower cost to acquire more comprehensive, sufficient and reliable information and make the flowability of resources stronger and efficiency higher. Thus, the government is able to give full play to its advantage of overall coordination. Thirdly, in order to resolve difficulty of some enterprises, arrange employment and increase financial revenue, the government can unveil some preferential policies, such as preference of discount of stock rights, alienation of land price and tax preference, etc, to improve the investment environment and promote reconstruction of automobile industry.

\subsection{Internal integration of enterprises after reconstruction of automobile industry in China}

Reconstruction of automobile enterprises is a "double-edged sword". On one hand, reconstruction is able to improve market structure, reduce production cost, increase industrial profits, enhance market concentration and enlarge market shares. On the other hand, blind reconstruction and incomplete integration of enterprises may also get enterprises trapped in a financial crisis or operation predicament. For the time being, cases of reconstruction all over the world are on a daily increase, but rate of success is low. The primary reason for this situation is that enterprises of reconstruction ignore integration of resources in all aspects after the reconstruction. Integration is a complex and long process, so it requires a rational and perfect planning at the earliest of the reconstruction.

\subsection{External communication}

In addition to internal integration of enterprises, reconstruction also involves integration of resources outside the enterprises, which is mainly realized through external communication. The subjects of external communication include clients, investors, potential clients, intermediary agents and suppliers of raw material, etc. Different communication means and content should be employed for different subjects. The target of external communication is to let the public come to know about happening of the reconstruction and new changes brought to the enterprises by the reconstruction through all kinds of communications, and, meanwhile, to diminish the negative image of the reconstruction on the public, set up a new image for the enterprises and enable investors and the public to take an interest in the enterprises and their products. In order to fulfill this target, those who conduct the reconstruction may adopt the following two kinds of communication channels. The first sort of communication is private communication. This kind of communication is limited in terms of the scope, but its content of communication is more profound and is more likely to achieve the target of communication. As for those important communication objects (such as, the major investors, the government and important clients, etc.), this kind of private communication is appropriate. The second kind of communication is public communication. This kind of communication is likely to rapidly disseminate information, but it is weak in pertinence, lacking in interactivity and is not good in effects of communication. The public declaration for some information or the news conference belong to public communication. The sequence of external communication is also quite significant. Usually, communication with investors and publicity of the information to the social public should be finished at the earliest so as to collect funds required for the reconstruction. Communication with clients and suppliers then may come afterwards and the effect will be better if communication with clients and suppliers is made when integration of products is almost finished.

\section{References}

Chen, Jia. (2009). An Analysis of Influence on China Automobile Industry by Foreign Investment Based on Global Value Chain Theory. Coastal enterprises and Science and Technology, (1).

Gao, Liangmou. (2009). On Post-Merger Integration: Cases and Strategies. Research on Financial and Economic Issues, (9).

Li, Junfeng. (2009). Analysis of the Influence on Safety of China's Automotive Industry Caused by Foreign Capitals M \& A. Enterprise Economy, (1).

Lu, Haiping. (2004). Excessive Expansion and Regroup for China's Automotive Industry. Automobile Tribune, (1).

Ye, Junmei. (2009). Based on Economics of Scale Theory of China's Auto Industry Compectiveness Study. Journal of Harbin University of Commerce (Social Science Edition), (2). 